\title{
CYTOREDUCTIVE SURGERY FOR ADVANCED-STAGE OVARIAN CANCER
}

\author{
Slavchev S., E. Ismail \\ Clinic of Gynecology, Department of Obstetrics and Gynecology, Medical University of Varna
}

\begin{abstract}
Usually, ovarian cancer develops asymptomatically. Nearly 30\%-40\% of the newly-diagnosed cases are already at III-IV stage of FIGO. In such patients, there are metastases on the peritoneum of the whole abdominal cavity. The survival rate of the patients with advanced ovarian cancer directly depends on the residual tumour after surgery. This review considers the place and role of cytoreductive surgery in the treatment of advanced ovarian carcinoma.
\end{abstract}

Key words: ovarian cancer, cancer stages, cytoreductive surgery, debulking surgery, survival rate

Ovarian cancer represents the greatest clinical challenge among all the gynecological malignancies. Epithelial cancers are the most common ovarian malignancies. Usually, they remain asymptomatic prior to the development of metastases. That is why, two-thirds of the patients present with an advanced disease at diagnosis. Ovarian cancer has the highest mortality rate of all the gynecological malignant neoplasms. In the U.S.A., there are annually 23,300 new cases and 13,390 women die from this disease (14). A woman's risk at birth of having ovarian cancer sometime later in her life is nearly $1,5 \%$, and that of dying from ovarian cancer is almost $1 \%(18)$.

\section{Epithelial ovarian cancer}

Approximately $90 \%$ of ovarian cancers are derived from tissues that come from the coelomic epithelium or mesothelium (18). The cells are a product of the primitive mesoderm, which may undergo metaplasia. Neoplastic transformation can occur when the cells are either genetically predisposed to oncogenesis, or are exposed to oncogenic agents (4). The patients with epithelial ovarian cancer in advanced stages determined by the initial exploratory laparotomy should undergo cytoreductive surgery to remove as much of the tumour mass and metastatic lesions $(1-3,5-13,19,20)$.

The operation to remove the primary tumour and metastatic lesions is called debulking surgery. Usually, it includes a total abdominal hysterectomy and bilateral salpingooophorectomy, with a complete omentectomy and resection of any metastatic lesions from the peritoneal surface and intestines. Usually, the pelvic tumour directly involves the rectosigmoid colon, terminal ileum and caecum. In a small number of patients, the disease is confined to the pel-

Address for correspondence

E. Ismail, Clinic of Gynecology, Dept. of Obstetrics and Gynecology, Medical University of Varna,

55 Marin Drinov Str., 9002 Varna

e-mail: elibet@abv.bg vic organs and the omentum, so that the removal of organs will result in extirpation of the tumour masses being associated with increased likelihood of prolonged survival. Often, ascites disappears completely after the removal of the primary tumour and omentum as well. It leads to nausea relief and rapid satiety that most patients experience, too.

The removal of the intestinal metastases can restore the adequate intestinal function and thus improve the overall status of the patient and the tolerance to subsequent chemotherapy. The large bulky tumours may contain areas with poor vascularization and, therefore, will be exposed to suboptimal concentration of chemotherapeutic agents. These areas are poorly oxygenated, so that radiotherapy, which requires adequate oxygenation to achieve maximum apoptosis will be less effective. Therefore, the surgical removal of the huge tumours results in elimination of the areas resistant to treatment. In addition, larger tumour masses consist of a high percentage of cells in the resting phase, i. e. non-dividing (G0 cells) and are resistant to therapy. A low growth fraction is characteristic of bulky tumours and cytoreductive surgery reduces the residual masses and increases the growth fraction.

\section{Goals of cytoreductive surgery}

The principal goal of cytoreductive surgery is the removal of the whole primary cancer and, if possible, any metastatic diseases. If resection of all the metastases is not possible, the aim is to reduce the tumour to an optimal status. The definition of optimal tumour resection varies. However, it consists in a lack of residual tumour or residual tumour masses less than 1-2 cm in greatest diameter of the lesion. The surgery for reducing the tumour masses is beneficial only if optimal cytoreduction is achieved. Women with minimal residual tumour have

20 months on average better survival than those who have undergone suboptimal cytoreductive surgery $(10,11)$.

It has initially been proposed that any metastatic nodules should be reduced to $<1,5 \mathrm{~cm}$ in maximal diameter and 
shown that, in this case, survival is significantly longer in patients for whom this was achieved (9). Later on, it was demonstrated that patients whose largest residual tumour lesion was $<5 \mathrm{~mm}$ presented with the highest survival rate $(10,11)$ and this was subsequently confirmed by other authors (20). The average survival in this category of patients was 40 months compared with 18 months for patients whose lesions were $<1,5 \mathrm{~cm}$ and 6 months for patients with nodules $>1,5 \mathrm{~cm}$. The patients whose malignant neoplasm had been completely resected and all the macroscopic lesions had disappeared presented with best overall survival rate. The resectability of the metastatic tumours is determined by their location.

Optimal cytoreduction is difficult to achieve in the presence of widespread metastases on the diaphragm, in the liver parenchyma, in the base of the mesentery, in the smaller omentum and in the porta hepatis. The capacity of cytoreductive surgery to improve survival depends on the size of metastases prior to cytoreduction, probably because of the presence of phenotypically resistant clones of cells in the large metastatic masses. The patients whose metastatic tumour is very large ( $>10 \mathrm{~cm}$ before cytoreduction) have shorter survival than those with smaller tumour masses (10). Extensive carcinomatosis, the presence of ascites, poor tumour grade, even with lesions $<5 \mathrm{~mm}$ shorten the survival rate (8).

The basic principle of most foreign studies and of our own ones concerning the removal of the pelvic tumour consists in the application of the retroperitoneal approach. Very often, it requires resection of the intestine, bladder and reanastomosis of the ureters. Our own and foreign retrospective studies show that these operations are feasible for $70-90 \%$ of the cases, especially, when performed by oncogynecologists. An optimal cytoreduction can be achieved in $60-75 \%$ of the patients operated by oncologists and gynecologists $(5,17)$. The performance of a pelvic and paraaortic lymph node dissection in the patients with stage III to IV prolongs survival rate $(5,17)$. Lymph node metastases were established in $33 \%$ of the cases with lymph node dissection as in $50 \%$ of the cases there were more than one metastasis (15). This fact and the high incidence rate of parametrial and vaginal invasion (33\%) justifies a lymph node dissection and radical hysterectomy of class II-III in primary surgical treatment of advanced ovarian cancer, not only for staging, but also as therapeutic procedure (15). The high incidence rate of metastases of the omentum from the same study corresponds to the incidence of ascites and carcinomatosis of the peritoneum.

Thus it confirms the assumption that omentum is the most common location for dissemination of the intraabdominal ovarian cancer. That is why omentectomy should be done accurately and in ablastic way to the serosa of the colon transversum and large gastric curvature $(15,16)$. Besides routine performance of appendectomy should be included in the surgical treatment of advanced ovarian cancer as metastases are detected in more than $10 \%$ of normal-looking appendices (16).

\section{REFERENCES}

1. Berek, J. S., N. F. Hacker, L. D. Lagasse, R. S. Leuchter. Lower urinary tract resection as part of cytoreductive surgery for ovarian cancer.Gynecol. Oncol., 13, 1982, No 1, 87-92.

2. Berek, J. S., N. F. Hacker, L. D. Lagasse. Rectosigmoid colectomy and reanastomosis to facilitate resection of primary and recurrent gynecologic cancer.- Obstet. Gynecol., 64, 1984, No 5, 715-720.

3. Berek, J. S. Interval debulking of epithelial ovarian cancer: an interim measure.- New Engl. J. Med., 332, 1995, No 10, 675-677.

4. Berek, J. S., N. F. Hacker. Practical gynecologic oncology. $3^{\text {rd }}$ ed. Philadelphia, Lippincott, Williams \& Wilkins, 2000, 3-38.

5. Bristow, R. E., R. S. Tomacruz, D. K. Armstrong, E. L. Trimble, F. J. Montz. Survival effect of maximal cytoreductive surgery for advanced ovarian carcinoma during the platinum era: a meta-analysis.- J. Clin. Oncol., 20, 2002, No 5, 1248-1259.

6. Deppe, G., V. K. Malviya, G. Boike, A. Hampton. Surgical approach to diaphragmatic metastases from ovarian cancer.- Gynecol. Oncol., 24, 1986, No 2, 258-260.

7. Eisenkop, S. M., R. L. Friedman, H. J. $\mathrm{W}$ ang. Complete cytoreductive surgery is feasible and maximizes survival in patients with advanced epithelial ovarian cancer: a prospective study.- Gynecol. Oncol., 69, 1998, No 2, 103-108.

8. Farias-Eisner, R., F. Teng, M. Oliveira, R. Leuchter, B. Karlan, L. D. Lagasse, et al. The influence of tumor grade, distribution and extent of carcinomatosis in minimal residual stage III epithelial ovarian cancer after optimal primary

cytoreductive surgery.- Gynecol. Oncol., 55, 1994, No 1, 108-110.

9. Griffiths, C. T. Surgical resection of tumor bulk in the primary treatment of ovarian carcinoma.- Natl. Cancer Inst. Monogr., 42, 1975, 101-104.

10. Hacker, N. F., J. S. Berek, L. D. Lagasse, R. K. Nieberg, R. M. Elashoff. Primary cytoreductive surgery for epithelial ovarian cancer.Obstet. Gynecol., 61, 1983, No 4, 413-420.

11. Hacker, N. F., J. S. Berek. Cytoreductive surgery in ovarian cancer.- In: Ovarian cancer. P. S. Albert, E. A. Surwit, eds. Boston, Martinus Nijhoff, 1986, 53-67.

12. Heintz, A. P. M., J. S. Berek. Cytoreductive surgery in ovarian cancer.- In: Ovarian cancer. M. S. Piver, ed. Edinburgh, Churchill Livingstone, 1987, 129-143.

13. Hunter, R. W., N. D. Alexander, W. P. Soutter. Meta-analysis of surgery in advanced ovarian carcinoma: is maximum cytoreductive surgery an independent determinant of prognosis?- $A m . J$. Obstet. Gynecol., 166, 1992, No 2, 504-511.

14. Jemal, A., A. Thomas, T. Murray, M. Thun. Cancer statistics, 2002.- CA Cancer J. Clin., 52, 2002, No 1, 23-47. 
15. Kornovski, Ya., G. Gorchev. Surgical treatment of ovarian cancer.- Oncologos, 2004, 16-21 (in Bulgarian).

16. Kornovski, Ya., R. Yaneva, D. Kornovski. Retroperitoneal approach and pelvic peritoneoectomy in surgical treatment of advanced ovarian cancer.- Akush. ginekol. (Sofia), 2006, No 6, 61-68 (in Bulgarian).

17. Piver, M. S., J. J. Barlow, S. B. Lele. Incidence of subclinical metastasis in stage I and II ovarian carcinoma.- Obstet. Gynecol., 52, 1978, No 1, 100-104.

18. Scully, R. E., R. H. Young, P. B. Clement. Tumors of the ovary, maldeveloped gonads, fallopian tube, and broad ligament.- In: Atlas of tumors pathology. Washington, Armed Forces Institute of Pathology, 1998, Fascicle $23,3^{\text {rd }}$ series.
19. van der Burg, M. E., M. van Lent, M. Buyse, A. Kobierska, N. Colombo, G. Favalli, et al. The effect of debulking surgery after induction chemotherapy on the prognosis in advanced epithelial ovarian cancer: an EROTC Gynecologic Cancer Cooperative Group of the European Organization for Research and Treatment of Cancer.- New Engl. J. Med., 332, 1995, No 10, 629-634.

20. Van Lindert, A. M., G. J. Alsbach, J. W. Barents, et al. The role of the abdominal radical tumor reduction procedure (ARTR) in the treatment of ovarian cancer.- In: Surgery in gynecologic oncology. A. P. M. Heintz, C. T. Griffiths, J. B. Trimbos, eds. The Hague, Martinus Nijhoff, 1984, 275-287. 